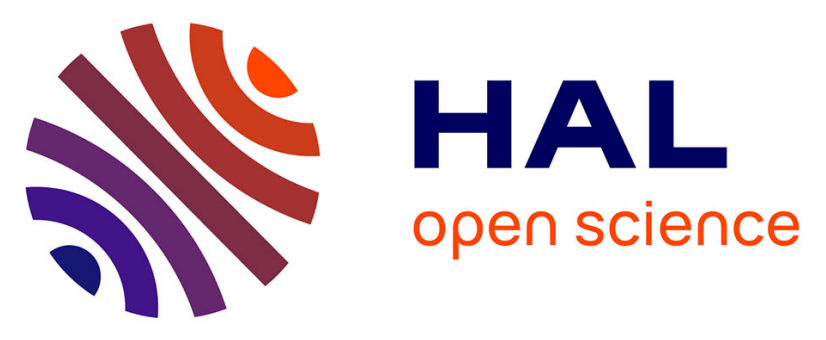

\title{
Information and Communication Technologies for Development. Strengthening Southern-Driven Cooperation as a Catalyst for ICT4D
}

Petter Nielsen, Honest Christopher Kimaro

\section{- To cite this version:}

Petter Nielsen, Honest Christopher Kimaro. Information and Communication Technologies for Development. Strengthening Southern-Driven Cooperation as a Catalyst for ICT4D: 15th IFIP WG 9.4 International Conference on Social Implications of Computers in Developing Countries, ICT4D 2019, Dar es Salaam, Tanzania, May 1-3, 2019, Proceedings, Part II. Springer International Publishing, AICT-552, 2019, IFIP Advances in Information and Communication Technology, 978-3-030-19114-6. 10.1007/978-3-030-19115-3 . hal-02281290

\section{HAL Id: hal-02281290 \\ https://hal.inria.fr/hal-02281290}

Submitted on 9 Sep 2019

HAL is a multi-disciplinary open access archive for the deposit and dissemination of scientific research documents, whether they are published or not. The documents may come from teaching and research institutions in France or abroad, or from public or private research centers.
L'archive ouverte pluridisciplinaire HAL, est destinée au dépôt et à la diffusion de documents scientifiques de niveau recherche, publiés ou non, émanant des établissements d'enseignement et de recherche français ou étrangers, des laboratoires publics ou privés.

\section{(c)(1)}

Distributed under a Creative Commons Attribution| 4.0 International License 


\section{IFIP Advances in Information and Communication Technology}

\section{Editor-in-Chief}

Kai Rannenberg, Goethe University Frankfurt, Germany

\section{Editorial Board Members}

TC 1 - Foundations of Computer Science

Jacques Sakarovitch, Télécom ParisTech, France

TC 2 - Software: Theory and Practice

Michael Goedicke, University of Duisburg-Essen, Germany

TC 3 - Education

Arthur Tatnall, Victoria University, Melbourne, Australia

TC 5 - Information Technology Applications

Erich J. Neuhold, University of Vienna, Austria

TC 6 - Communication Systems

Aiko Pras, University of Twente, Enschede, The Netherlands

TC 7 - System Modeling and Optimization

Fredi Tröltzsch, TU Berlin, Germany

TC 8 - Information Systems

Jan Pries-Heje, Roskilde University, Denmark

TC 9 - ICT and Society

David Kreps, University of Salford, Greater Manchester, UK

TC 10 - Computer Systems Technology

Ricardo Reis, Federal University of Rio Grande do Sul, Porto Alegre, Brazil

TC 11 - Security and Privacy Protection in Information Processing Systems

Steven Furnell, Plymouth University, UK

TC 12 - Artificial Intelligence

Ulrich Furbach, University of Koblenz-Landau, Germany

TC 13 - Human-Computer Interaction

Marco Winckler, University of Nice Sophia Antipolis, France

TC 14 - Entertainment Computing

Rainer Malaka, University of Bremen, Germany 


\section{IFIP - The International Federation for Information Processing}

IFIP was founded in 1960 under the auspices of UNESCO, following the first World Computer Congress held in Paris the previous year. A federation for societies working in information processing, IFIP's aim is two-fold: to support information processing in the countries of its members and to encourage technology transfer to developing nations. As its mission statement clearly states:

IFIP is the global non-profit federation of societies of ICT professionals that aims at achieving a worldwide professional and socially responsible development and application of information and communication technologies.

IFIP is a non-profit-making organization, run almost solely by 2500 volunteers. It operates through a number of technical committees and working groups, which organize events and publications. IFIP's events range from large international open conferences to working conferences and local seminars.

The flagship event is the IFIP World Computer Congress, at which both invited and contributed papers are presented. Contributed papers are rigorously refereed and the rejection rate is high.

As with the Congress, participation in the open conferences is open to all and papers may be invited or submitted. Again, submitted papers are stringently refereed.

The working conferences are structured differently. They are usually run by a working group and attendance is generally smaller and occasionally by invitation only. Their purpose is to create an atmosphere conducive to innovation and development. Refereeing is also rigorous and papers are subjected to extensive group discussion.

Publications arising from IFIP events vary. The papers presented at the IFIP World Computer Congress and at open conferences are published as conference proceedings, while the results of the working conferences are often published as collections of selected and edited papers.

IFIP distinguishes three types of institutional membership: Country Representative Members, Members at Large, and Associate Members. The type of organization that can apply for membership is a wide variety and includes national or international societies of individual computer scientists/ICT professionals, associations or federations of such societies, government institutions/government related organizations, national or international research institutes or consortia, universities, academies of sciences, companies, national or international associations or federations of companies.

More information about this series at http://www.springer.com/series/6102 
Petter Nielsen · Honest Christopher Kimaro (Eds.)

\section{Information}

and Communication

Technologies

for Development

Strengthening

Southern-Driven Cooperation

as a Catalyst for ICT4D

15th IFIP WG 9.4 International Conference

on Social Implications of Computers

in Developing Countries, ICT4D 2019

Dar es Salaam, Tanzania, May 1-3, 2019

Proceedings, Part II

黛 Springer 


\section{Editors}

Petter Nielsen (1D

University of Oslo

Oslo, Norway

\author{
Honest Christopher Kimaro \\ University of Dar es Salaam \\ Dar es Salaam, Tanzania
}

ISSN 1868-4238 ISSN 1868-422X (electronic)
IFIP Advances in Information and Communication Technology
ISBN 978-3-030-19114-6
https://doi.org/10.1007/978-3-030-19115-3

(C) IFIP International Federation for Information Processing 2019

This work is subject to copyright. All rights are reserved by the Publisher, whether the whole or part of the material is concerned, specifically the rights of translation, reprinting, reuse of illustrations, recitation, broadcasting, reproduction on microfilms or in any other physical way, and transmission or information storage and retrieval, electronic adaptation, computer software, or by similar or dissimilar methodology now known or hereafter developed.

The use of general descriptive names, registered names, trademarks, service marks, etc. in this publication does not imply, even in the absence of a specific statement, that such names are exempt from the relevant protective laws and regulations and therefore free for general use.

The publisher, the authors and the editors are safe to assume that the advice and information in this book are believed to be true and accurate at the date of publication. Neither the publisher nor the authors or the editors give a warranty, expressed or implied, with respect to the material contained herein or for any errors or omissions that may have been made. The publisher remains neutral with regard to jurisdictional claims in published maps and institutional affiliations.

This Springer imprint is published by the registered company Springer Nature Switzerland AG The registered company address is: Gewerbestrasse 11, 6330 Cham, Switzerland 


\section{Preface}

This book is a collection of papers presented at the 15th International Conference on Social Implications of Computers in Developing Countries (IFIP WG 9.4 2019 Conference) held in Dar es Salaam, Tanzania, May 1-3, 2019. The theme of the conference, "Strengthening Southern-Driven Cooperation as a Catalyst for ICT4D," sought to stimulate and encourage critical discussions on the different facets of Southern-driven cooperation, its promises, potential for creating a better world, and the challenges we face in achieving the promised potential.

With the proliferation of ICT-related projects to support development, countries from the south are now emerging as important innovators and actors in the global development and adoption of ICT for community and economic growth. A good example is how Kenya and Tanzania have been leading the world with mobile payments for several years. The mobile payment services have supported micro financing and transformed economic activities and lives within the local communities and beyond. Such impacts offer an exciting setting for reverse innovation whereby lessons learned in ICT4D could offer rich insights for information systems research in general. Furthermore, strengthening a southern-driven cooperation promotes ICT initiatives and research carried out in and by developing countries. The conference, therefore, aimed at offering context-rich theories, methodologies and practical guidance on the use of ICTs to empower local communities.

Toward this goal, a request for track proposals was issued. After the evaluation we arrived at 11 tracks and two workshops, namely, Early Feedback to Early Career Researchers and the PhD Day Workshop. Only the research papers (97 full papers and two short papers) are included in this collection. The paper tracks were: Digital Platforms for Development; FinTech and Development; ICT4D for the Indigenous, by the Indigenous and of the Indigenous; Recognizing African Expression of Tech; Harnessing Agriculture; Land Administration and Public Financial Management for ICT4D; ICT for Displaced Population: How it helps, How it hurts; Communities, ICT-Enabled Networks, and Development; Pushing the Boundaries-New Research Methods, Theory and Philosophy in ICT4D; Southern-Driven Human-Computer Interaction; Locally Developed Process and Method Innovations in ICT4D; Sustainable ICT; Informatics, Education and Learning in a Turbulent World- "Doing the Safari Way."

We received a total of 185 qualified papers from 46 countries, which were then sent for peer review. A double-blind peer review process was followed with each paper receiving an average of two reviews. The rigorous review process comprised 328 reviews, 248 of which came from 171 external reviewers. Of the 185 reviewed contribution, 99 were accepted and presented at the conference and are thus included in this collection.

For a large event like this conference to happen, a considerable effort by numerous individuals is required. We begin by thanking all the Program Committee members, the 
local arrangements chairs, and 171 additional reviewers for their enormous efforts in reviewing the submitted papers. We also express gratitude to all the sponsors: the IFIP WG 9.4 (ifipwg94.org), International Network for Postgraduate Students in the area of ICT4D (IPID, ipid.se), University of Oslo (UiO), College of ICT (CoICT) of the University of Dar es Salaam, Tanzania Telecommunication Corporation Limited (TTCL), UNICEF Tanzania, and several others. It was a great pleasure to hold the IFIP WG 9.4 2019 Conference in Dar es Salaam, Tanzania.

May 2019

Petter Nielsen

Honest Christopher Kimaro 


\section{Organization}

\section{General Chairs}

Nerey H. Mvungi

Sundeep Sahay
University of Dar es Salaam, Tanzania

University of Oslo, Norway

\section{Program Committee Chairs}

Petter Nielsen

Honest C. Kimaro

\section{Steering Committee}

Mussa Kissaka

Prosper Mafole

Wilfred Senyoni

Honest Kimaro

Nerey Mvungi

Abdulla Ally

Joel Mtebe

Petter Nielsen

Ellen Kalinga

Kwame Ibwe

Libe Massawe

Abdi Abdalla

Sundeep Sahay

\section{Program Committee}

John Sören Pettersson

Brian Nicholson

Prosper Mafole

Petter Nielsen

Johan Sæbø

Wilfred Senyoni

Nima Shidende

Devinder Thapa

Arunima Mukherjee

Antonio Diaz Andrade

Ellen Kalinga

Abdi Talib

Suzana Brown
University of Oslo, Norway

University of Dar es Salaam, Tanzania

University of Dar es Salaam, Tanzania

University of Dar es Salaam, Tanzania University of Oslo, Norway

University of Dar es Salaam, Tanzania University of Dar es Salaam, Tanzania University of Dar es Salaam, Tanzania University of Dar es Salaam, Tanzania University of Oslo, Norway

University of Dar es Salaam, Tanzania University of Dar es Salaam, Tanzania University of Dar es Salaam, Tanzania University of Dar es Salaam, Tanzania University of Oslo, Norway

Karlstad University, Sweden

Manchester Business School, UK

University of Dar es Salaam, Tanzania

University of Oslo, Norway

University of Oslo, Norway

University of Oslo, Norway

University of Dodoma, Tanzania

University of Agder, Norway

University of oslo, Norway

Auckland University of Technology, New Zealand University of Dar es Salaam, Tanzania

University of Dar es Salaam, Tanzania

SUNY, South Korea 
Terje Sanner

P. J. Wall

Elizaphan Maina

Mikko Ruohonen

Reima Suomi

Faheem Hussain

Rehema Baguma

Marita Turpin

Harminder Singh

Amber Young

Angsana

Techatassanasoontorn

Richard Heeks

Jose Abdelnour-Nocera

Javier Osorio

Nicholas Blessing

Mavengere

Stan Karanasios

Gertjan Van Stam

Paul Van Asperen

Kirstin Krauss

Faraja Igira

Emmanuel Eilu

Machdel Matthee

Rita Orji

Laura Hosman

Sandip Sarkar

Ebenezer Laizer

Rohan Bennett

Tegawendé F. Bissyandé

Mussa Kissaka

Honest Kimaro

Nerey Mvungi

Abdulla Ally

Joel Mtebe

Kwame Ibwe

Libe Massawe

Sundeep Sahay

Omar Hamad
University of Oslo, Norway

Trinity College Dublin, Ireland

Kenyatta University, Kenya

Tampere University, Finland

University of Turku, Estonia

Arizona State University, USA

Uganda Technology and Management University, Uganda

University of Pretoria, South Africa

Auckland University of Technology, New Zealand

University of Arkansas, USA

Auckland University of Technology, New Zealand

The University of Manchester, UK

University of West London, UK

Las Palmas de Gran Canaria University, Spain

Tampere University, Finland

RMIT University, Australia

Nelson Mandela Metropolitan University, South Africa

University of Twente, The Netherlands

University of South Africa, South Africa

Institute of Finance Management, Tanzania

Makerere University, Uganda

University of Pretoria, South Africa

Dalhousie University, Canada

Arizona State University, USA

University of Arkansas, USA

University of Turku, Estonia

Swinburne University, Australia

University of Luxembourg, Luxembourg

University of Dar es Salaam, Tanzania

University of Dar es Salaam, Tanzania

University of Dar es Salaam, Tanzania

University of Dar es Salaam, Tanzania

University of Dar es Salaam, Tanzania

University of Dar es Salaam, Tanzania

University of Dar es Salaam, Tanzania

University of Oslo, Norway

Zanzibar University, Tanzania 


\section{Contents - Part II}

\section{Pushing the Boundaries - New Research Methods, Theory and Philosophy in ICT4D}

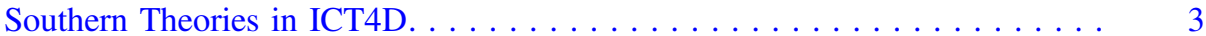

David Kreps and Julian M. Bass

Combining Pragmatism and Critical Realism in ICT4D Research:

An e-Resilience Case Example . . . . . . . . . . . . . . . . . . . . . . 14

Richard Heeks, Angelica V. Ospina, and P.J. Wall

Digital Development: Elements of a Critical ICT4D Theory and Praxis . . . . . Anna Bon and Hans Akkermans

Identifying Generative Mechanisms in a Mobile Health (mHealth) Project in Sierra Leone: A Critical Realist Framework for Retroduction . . . . . . . . . . P.J. Wall, Dave Lewis, and Lucy Hederman

Capabilities and Affordances in the ICT4D Context: Similarities,

Differences, and Complementarities. . . . . . . . . . . . . . . . . . .

Devinder Thapa and Yingqin Zheng

A Framework to Explain the Relation Between ICT and Development:

Combining Affordances and the Capability Approach .

Mathias Hatakka, Øystein Sabø, and Devinder Thapa

Method of Research in a We-Paradigm, Lessons on Living

Research in Africa. . . . . . . . . . . . . . . . . . . . . . . .

Gertjan van Stam

Unpacking Empowerment in ICT4D Research . . . . . . . . . . . . . . .

Priyanka Pandey and Yingqin Zheng

Adopting a Theory of Change Approach for ICT4D Project Impact

Assessment - The Case of CMES Project. . . . . . . . . . . . . . . . .

Yan Li and Manoj A. Thomas

Participatory Video, Giving Voice and Respect to the Epistemic

Sovereignty of Communities in Rural Zimbabwe . . . . . . . . . . . . . .

Peter Makamba, Chido Matewa, Janneke van Dijk, Gertjan van Stam, and Peter Vhoko 
Mechanisms Fostering the Misuse of Information Systems for Corrupt

Practices in the Nigerian Public Sector. . . . . . . . . . . . . .

Ibrahim Inuwa, Chidi Ononiwu, Muhammadou M. O. Kah, and Ago K. M. Quaye

Rethinking Theory and Practice of ICT4D. An Analysis of the Discourse

Embedded in the 2016 World Bank Report . . . . . . . . . . . . . . . .

Calisto Kondowe and Wallace Chigona

\section{ICT4D for the Indigenous, by the Indigenous and of the Indigenous}

Nexus Between Country Context and the Role of External Actors

in the Formulation of National Information and Communication

Technology Policies . . . . . . . . . . . . . . . . . . .

Gregory Kunyenje and Wallace Chigona

Research in Africa for Africa? Probing the Effect and Credibility

of Research Done by Foreigners for Africa . . . . . . . . . . . . . .

Munyaradzi Mawere and Gertjan van Stam

Decolonising Neo-Liberal Innovation: Using the Andean Philosophy

of 'Buen Vivir' to Reimagine Innovation Hubs . . . . . . . . . . . . . . . .

Andrea Jimenez and Tony Roberts

Incorporating Indigenous Perspectives in Provision of E-government

Services: The Case of Tanzania . . . . . . . . . . . . . . . . .

Bakari Mashaka, Neil McBride, and Kutoma Wakunuma

Smart City for Development: A Conceptual Model

for Developing Countries . . . . . . . . . . . . . . . . . . . . . . .

Luiz Antonio Joia and Alexander Kuhl

Digital Technology for Preserving Cultural Heritage in Tonga . . . . . . . . . . .

'Anau Mesui, Antonio Diaz Andrade, and Lena Waizenegger

\section{Southern-Driven Human-Computer Interaction}

Socio-Technical HCI for Ethical Value Exchange: Lessons from India. . . . . . José Abdelnour-Nocera, Torkil Clemmensen, Morten Hertzum, Dineshkumar Singh, and Veerendra Veer Singh

Usability Problems and Obstacles to Addressing Them in Health Information Software Implementations . . . . . . . . . . . . . . Magnus Li 
Human-Computer Interaction for Development (HCI4D): The Southern

African Landscape . . . . . . . . . . . . . . . . . . . . .

Judy van Biljon and Karen Renaud

A Local Perspective: Working an Agricultural Information Service into a Rural Community . . . . . . . . . . . . . . . . . . . . . . . . .

Lars Rune Christensen, Hasib Ahsan, Mamunur Rashid, and Badal Kumar Das

Digital Wallets 'Turning a Corner' for Financial Inclusion: A Study of Everyday PayTM Practices in India. . . . . . . . . . . . . . . .

Tanmay Joshi, Sharmistha Swasti Gupta, and Nimmi Rangaswamy

Research in Progress: Holistic Climate Service Prototypes for Farmers in Tambuu, Tanzania. . . . . . . . . . . . . . . . . . . . . . . . .

Ville Myllynpää, Jaakko Helminen, Ezra Misaki, Mikko Apiola, Jani Haakana, Tomi Westerlund, and Erkki Sutinen

Factors that Influence Workers' Participation in Unhygienic Cyber Practices: A Pilot Study from Nigeria . . . . . . . . . . . . . . . . .

Princely Ifinedo, Nigussie Mengesha, and Olumide Longe

Investigating the Adoption of an Integrated Hospital Information System in Rural Uganda: A Case of Kisiizi Hospital . . . . . . . . . . . . . . . . . . . . .

Amos Baryashaba, Angella Musimenta, Samuel Mugisha, and Leonard Peter Binamungu

Using PESTELMO to Frame HCI Contextual Development

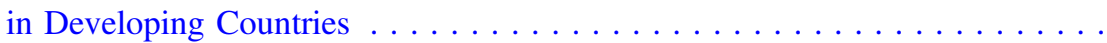

Catherine G. Mkude and Maria A. Wimmer

\section{Sustainable ICT, Informatics, Education and Learning in a Turbulent World - "Doing the Safari Way"}

Information Systems Education for Development: A Typology of ICT4D Pedagogies . . . . . . . . . . . . . . . . . . . . Gwamaka Mwalemba

Data Science Postgraduate Education at University of Dar es Salaam in Tanzania: Current Demands and Opportunities Betty Mbwilo, Honest Kimaro, and Godfrey Justo

The Role of Human Centered Design (HCD) and Challenge Driven Education in Enhancing the Innovation Capacity of Africa's Young People: Case of Youth for Children (Y4C) Innovation Hub in Tanzania . . . . . . . . . . Hellen Maziku, Joseph Cosmas, Norah Maki, Honest Kimaro, and Charles Otine 
Towards Developing Interactive Content for Enhancing Life Skills

Education in Tanzania: Possibilities and Pitfalls . . . . . . . . . . . . .

Christian M. Budoya, Mussa M. Kissaka, and Joel S. Mtebe

Community-Centered, Project-Based ICT4D Education in the Field. . . . . . . . 386 Anna Bon, Jaap Gordijn, Hans Akkermans, Victor de Boer, André Baart, Cheah Wai Shiang, and Sze San Nah

Building Sustainable Collaborations and Academic Networks in Low Income Countries: Case of Master Programmes . . . . . . . . . . . . . . . . . . 398 Jens Kaasbøll, Chipo Kanjo, and Honest Kimaro

Information and Communication Technology in Mathematics Education Integration Readiness in Tanzania Higher Education Institutions . . . . . . . . . Mzomwe Yahya Mazana, Calkin Suero Montero, and Solomon Sunday Oyelere

eLearning in an African Place: How 'Alien' eLearning Models Are Failing Many in Africa. ............................ Munyaradzi Mawere and Gertjan van Stam

Developing Multimedia Enhanced Content to Raise HIV/AIDS

Awareness to Children. . . . . . . . . . . . . . . . . . . . . .

Patricia Makuru, Fatuma Simba, and Ellen Kalinga

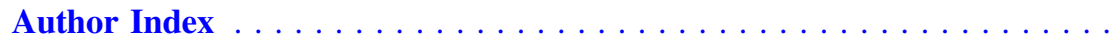




\section{Contents - Part I}

\section{Communities, ICT-Enabled Networks, and Development}

The Ins and Outs of Participation in a Weather Information System . . . . . .

Bidisha Chaudhuri and Linus Kendall

eHealth in Zimbabwe, a Case of Techno-Social Development. . . . . . . . . . .

Trymore Chawurura, Ronald Manhibi, Janneke van Dijk, and Gertjan van Stam

ICT Use in the Context of Electricity Access in a Developing Country:

A Choice Framework Analysis . . . . . . . . . . . . . . . . . .

Arlene Bailey, Aldrie Henry-Lee, Yhanore Johnson-Coke, Richard Leach, Anthony Clayton, Matt Gee, and Oliver Browne

An Inquiry into IT Governance in Healthcare Organizations in Uganda . . . . . Michael Kizito

Exploring an Impact Sourcing Initiative for a Community of People with Disabilities: A Capability Analysis...................

Karsten Eskelund, Richard Heeks, and Brian Nicholson

System Use and User Satisfaction in the Adoption of Electronic Medical

Records Systems: A Case of DHIS2 Tracker Implementation in Tanzania . . .

Immaculate Ayebazibwe, Honest C. Kimaro, and Jens J. Kaasbøll

Contemporary Challenges in Street Trader-Customer Interaction Through

Mobile Devices in Dodoma, Tanzania . . . . . . . . . . . . . . . . .

Joel Rumanyika, Matti Tedre, Mikko Apiola, Solomon Sunday Oyelere, and Nasibu Rajabu Mramba

Value Co-creation in Design of mHealth Applications for Maternal

Healthcare Service Delivery . . . . . . . . . . . . . . . . .

Hawa Nyende

A Framework for Understanding the Empowerment Effects of Telecentres on Rural Communities in Developing Countries . . . . . . . . . . . . . . . .

Sellina Khumbo Kapondera, Roberta Bernadi, and Niki Panteli

Leveraging Digital Health Platforms in Developing Countries: The Role of Boundary Resources . . . . . . . . . . . . . . . . . . . .

Brown Msiska, Petter Nielsen, and Jens Kaasboll 
ICT Enabled Peace Network: Case Study of Conflict Early Warning System

in Kenya ..............................

Arunima Mukherjee and Festus Mukoya

E-Commerce Institutionalisation in Mozambique: Enablers and Barriers . . . . . Fernanda Matsinhe and Salah Kabanda

The Influence of Telecentres on the Economic Empowerment of the Youth

in Disadvantaged Communities of South Africa . . . . . . . . . . . . . .

Samkelo Lutho Booi, Wallace Chigona, Priscilla Maliwichi, and Khaya Kunene

Peer Networking and Capacity Building for Child Protection Professionals

- Lessons from "ChildHub" . . . . . . . . . . . . . . . . . . . . .

Sendrine Constant, Balwant Godara, Thierry Agagliate,

Nihaalini Kumar, and Amara Amara

Investigating the Implementation of ICT Tool to Electoral Process

in Nigeria. . . . . . . . . . . . . . . . . . . . . . . . . .

Aishatu Shuaibu, Salihu Dasuki, and Muhammadou Kah

\section{Digital Platforms for Development}

A Multi-level Perspective on Digital Platform Implementation and Impact:

The Case of EasyTaxi in Colombia . . . . . . . . . . . . . . . . . .

Juan Erasmo Gomez-Morantes, Richard Heeks, and Richard Duncombe

Exploring Tensions of Global Public Good Platforms for Development:

The Case of DHIS2 . . . . . . . . . . . . . . . . . . . . . .

Brian Nicholson, Petter Nielsen, Johan Saebo, and Sundeep Sahay

Software Platforms for Inclusive Innovation . . . . . . . . . . . . . . . .

Terje Aksel Sanner and Petter Nielsen

The Role of Digital Platforms in Disrupting Agricultural Value Chains

in Developing Countries . . . . . . . . . . . . . . . . . . . . . .

Bookie Ezeomah and Richard Duncombe

Sharing Economy Digital Platforms and Social Inclusion/Exclusion:

A Research Study of Uber and Careem in Pakistan . . . . . . . . . . . . . .

Fareesa Malik and Zujaja Wahaj

Strategies for Standardizing Health Information Analysis: Flexible

Standards Revisited . . . . . . . . . . . . . . . . . . . . . .

Olav Poppe, Johan Ivar Sabø, and Jørn Braa 
An Institutional Perspective on the Adoption of Open Dashboard for Health Information Systems in Tanzania . . . . . . . . . . . . . .

Wilfred F. Senyoni, Honest C. Kimaro, Jørn Braa, and Claud Kumalija

Tracing the Impact of the City of Cape Town's Open Data Initiative

on Communities and Development . . . . . . . . . . . . . . . . . .

Mbongeni Hlabano and Jean-Paul Van Belle

Exploring Hybridity in Digital Social Entrepreneurship . . . . . . . . . . . Silvia Masiero and M. N. Ravishankar

What Motivates ICT4D Champions? . . . . . . . . . . . . . . Jaco Renken

Digital Platforms in the Global South: Foundations and Research Agenda . . . Kari Koskinen, Carla Bonina, and Ben Eaton

Scaling Across Functional Domains: A Case of Implementing an Electronic HIV Patient Information System in Sierra Leone. . . . . . . . . . . . . . . . . . . Eric Adu-Gyamfi, Petter Nielsen, Johan Ivar Sabø, and Zeferino Saugene

Mobile Phone Use for Empowerment and Well-Being of the Physically Challenged in Nigeria . . . . . . . . . . . . . . . . . .

Abdulrashid Iliya, Chidi G. Ononiwu, Muhammadou M. O. Kah, and Ago K. M. Quaye

Agile Software Development Practices in Egypt SMEs: A Grounded Theory Investigation . . . . . . . . . . . . . . . . .

Amr A. Mohallel and Julian M. Bass

Experiences from a Development Project in Kenya - Baselines for Future Climate Information Systems . . . . . . . . . . . . . . . . . . . .

Jaakko Helminen, Balozi Bekuta Kirongo, Silvia Gaiani, Ezra Misaki, Mikko Apiola, and Erkki Sutinen

How South African University Information Systems Students Are Using Social Media. . . . . . . . . . . . . . . . . . . . . . .

Yazeed Seedat, Sumarie Roodt, and Samwel Dick Mwapwele

Convergence of Technical and Policy Processes: A Study of Indonesia's Health Information Systems . . . . . . . . . . . . . . . . . . . . . .

Taufiq Sitompul, Wilfred Senyoni, Jørn Braa, and Yudianto

IT and Government Corruption in Developing Countries: A Literature

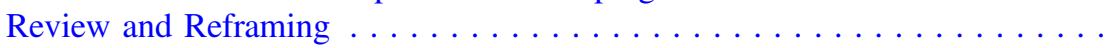

Atta Addo 
The Contributions of WhatsApp to Social Inclusion: A Case of Internally

Displaced Persons in Nigeria . . . . . . . . . . . . . . . .

Salihu Ibrahim Dasuki and Naima Hafiz Abubakar

Ride Hailing Regulations in Cali, Colombia: Towards Autonomous

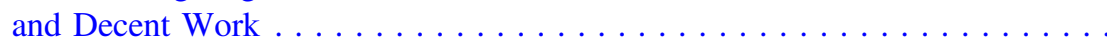

Katherine M. A. Reilly and Luis H. Lozano-Paredes

Ex-Ante Analysis of Adoption of Introduced Chicken Strains Among

Smallholder Farmers in Selected Areas of Tanzania. . . . . . . . . . . . . . . .

Rogers Andrew, Jeremia Makindara, Said H. Mbaga,

and Roselyne Alphonce

Assessing User-Designed Dashboards: A Case for Developing Data

Visualization Competency . . . . . . . . . . . . . . . . .

Aprisa Chrysantina and Johan Ivar Sabø

Is Inclusive Digital Innovation Inclusive? An Investigation

of M-Shwari in Kenya. . . . . . . . . . . . . . . . . . . . .

Wenxiu (Vince) Nan and M. Lynne Markus

Sinking Under Its Own Weight: Case of Aadhaar Mediated

Entitlements in India . . . . . . . . . . . . . . . . . . . . . . . . . .

Arunima Mukherjee and Sundeep Sahay

Design Science Research Strengthened: Integrating Co-creation

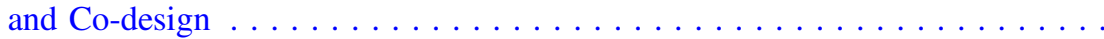

Calkin Suero Montero and Alsen Florian Kapinga

Institutional Shaping of Affordances: Implications on Information

Use in Global Humanitarian Organizations . . . . . . . . . . . . . . . . . . .

Marta Maria Vila-Pozo and Sundeep Sahay

Towards Holistic Mobile Climate Services for Farmers

in Tambuu, Tanzania. . . . . . . . . . . . . . . . . . . . . 508

Ville Myllynpää, Ezra Misaki, Mikko Apiola, Jaakko Helminen,

Moammar Dayoub, Tomi Westerlund, and Erkki Sutinen

Anti-corruption Efforts in National ICT Policies: A Study of Policy

Environments in Sub-Saharan Africa . . . . . . . . . . . . . . . . . . .

Cecilia Strand and Mathias Hatakka

Integrating Electronic Medical Records Data into National Health

Reporting System to Enhance Health Data Reporting and Use at the Facility Level . . . . . . . . . . . . . . . . . . . . . . . .

Bigten R. Kikoba, Ellen Kalinga, and Juma Lungo 
Recommendations for M-Government Implementation in Developing

Countries: Lessons Learned from the Practitioners. . . . . . . . . . . . . .

Tupokigwe Isagah and Maria A. Wimmer

Co-creating an ICT Artefact with Elderly Rural Women in Mafarafara:

A Social Structuration Account. . . . . . . . . . . . . . . . . . . . .

Ronel Smith, Marita Turpin, and Marlien Herselman

A Critical Analysis of the Implementation of Health Information Systems for Public Healthcare Service Delivery in Resource-Constrained Environments: A South African Study . . . . . . . . . . . . . . . . . . . . .

Mourine Achieng and Ephias Ruhode

Acceptability and Use of Mobile Health Applications in Health Information Systems: A Case of eIDSR and DHIS2 Touch Mobile Applications in Tanzania . . . . . . . . . . . . . . . . . . . . . . . . .

Jimmy T. Mbelwa, Honest C. Kimaro, and Bernard Mussa

The Experience of Chamwino Small-Scale Farmers on the Use of Smartphone in Farming Business, Tanzania . . . . . . . . . . . . . . . .

Ezra Misaki

Exploring the Effect of Mobile Apps on SMEs in Nigeria:

A Critical Realist Study . . . . . . . . . . . . . . . . . . . . .

Adedamola Tolani, Adebowale Owoseni, and Hossana Twinomurinzi

Evaluating mHealth Apps Using Affordances: Case of CommCare

Versus DHIS2 Tracker. . . . . . . . . . . . . . . . . . . .

Amrit Chhetri, Mari Iversen, Jens Kaasbøll, and Chipo Kanjo

Investigating the Efficiency of ICT Infrastructure Utilization: A Data

Envelopment Analysis Approach. . . . . . . . . . . . . . . . .

'Yinka Oyerinde and Felix Bankole

\section{ICT for Displaced Population and Refugees: How It Helps, How It Hurts}

Mobile Technology for Record Keeping by Women Entrepreneurs

in Tanzania: User Requirement Assessment . . . . . . . . . . . . . . . . . . .

William Clifford Gomera, Jarkko Suhonen, Solomon Sunday Oyelere, and Alsen Florian Kapinga

Reimagining Refugee Identity Systems: A Sociological Approach. . . . . . . . .

Shirin Madon and Emrys Schoemaker

'When Will You Start Teaching the REAL Curriculum?': Challenges and Innovations in Education for Rohingya Refugees . . . . . . . . . . . .

Azmina Karim and Faheem Hussain 
Refugees and ICTs: Identifying the Key Trends and Gaps

in Peer-Reviewed Scholarship. . . . . . . . . . . . . . . . . . .

Suzana Brown, Faheem Hussain, and Ali M. Masoumifar

\section{Local Technical Papers}

Rate Adaptive Congestion Control Using Lookup Table Scheme

to Enhance Quality of Experience . . . . . . . . . . . . . . . . .

Jane Lissah and Mercy Mbise

Enhancing Faults Monitoring in Secondary Electrical

Distribution Network . . . . . . . . . . . . . . . . . . . . .

Yona Andegelile, Godfrey Chugulu, Ally Bitebo, Hadija Mbembati, and Herald Kundaeli

Handover Management in Femtocell LTE Networks Under Fast

Varying Channels .

Catherine Protas and Kwame Ibwe

Trends and Opportunities for Traffic Engineering Paradigms Across Mobile

Cellular Network Generations . . . . . . . . . . . . . . . . . . . . . . . .

Khadija Mkocha, Mussa M. Kissaka, and Omar F. Hamad

Exploring the Impacts of Intrinsic Variables on Security Compliance

Efficiency Using DEA and MARS . . . . . . . . . . . . . . . . .

Charlette Donalds, Kweku-Muata Osei-Bryson, and Sergey Samoilenko

A Critical Review of Edge and Fog Computing for Smart

Grid Applications ...........................

Gilbert M. Gilbert, Shililiandumi Naiman, Honest Kimaro, and Burchard Bagile

Information Security Culture Assessment of Small and Medium-Sized

Enterprises in Tanzania . . . . . . . . . . . . . . . . . . . . . 776

Zainab Ruhwanya and Jacques Ophoff

Author Index 